\title{
Review Paper: The Role of Volunteer Citizens in Response to Accidents and Disasters
}

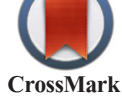

Mohsen Aminizade ${ }^{1 *}$, Mahmoud Nekouei Moghaddam², Mehdi Birami Jam ${ }^{1}$, Mostafa Shamsi ${ }^{3}$, Nader Majidi ${ }^{1}$, Nasir Amanat ${ }^{1}$, Seyed Hosein Hoseinii ${ }^{1}$

1. Research Center in Emergency and Disaster Health, University of Social Welfare and Rehabilitation Sciences, Tehran, Iran

2. Departments of Health Management, Faculty of Management and Information, Kerman University of Medical Sciences, Kerman, Iran.

3. Departments of Health Management, Marvdasht Branch, Islamic Azad University, Marvdasht, Iran.

\begin{tabular}{|l|l|l}
\hline $\begin{array}{c}\text { Use vourdevice to scan } \\
\text { and read the article online }\end{array}$ \\
unteer Citizens in Response to Accidents and Disasters. Health in Emergencies and Disasters Quarterly. 2017; 2(3): 107-124. \\
https://doi.org/10.18869/nrip.hdq.2.3.107 \\
doi: $:$ https://doi.org/10.18869/nrip.hdq.2.3.107
\end{tabular}

Article info:

Received: 12 Nov. 2016

Accepted: 18 Feb. 2017

\section{Keywords:}

Accidents and disasters,

Volunteers, Volunteer citizens

\begin{abstract}
Background: Many organizations, especially at the time of accidents, disasters, and critical conditions, cannot provide their services without the presence of volunteers. When accidents and disasters occur, the first persons who normally appear at the scene are citizens. Volunteer citizens with the skills and local knowledge can play important roles when accidents and disasters occur and can provide valuable assistance to the relief forces. The current article aimed at examining the role of volunteer citizens in response to accidents and disasters.
\end{abstract}

Materials and Methods: The current study examined the published articles from 2000 to 2016 based on the following keywords: informal volunteers in the disasters, challenges facing volunteer citizens in accidents and disasters, informal volunteers and disasters in local and foreign electronic databases including SID, Magiran, Iran Medex, ISC, Google Scholar, PubMed, ISI, and Scopus.

Results: Based on the search strategy, 50 articles were examined and the keywords, definitions, volunteer roles, role of volunteers in accidents and disasters, various types of informal voluntary activities, and volunteer citizens' participation were examined.

Conclusion: Studies referred to the roles, definitions, and challenges that informal volunteers face in various stages of accidents and disasters and the obvious point in the research was that more adaptive and comprehensive crisis and emergency management models are needed to utilize the capacities and flexibility of volunteers available within and between communities in disasters, and the network structure management can be helpful to manage the volunteers.

\section{Introduction}

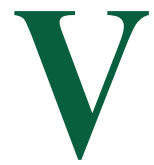

oluntary activities constitute a vital part of human community activities. The United Nations (UN) introduced them as activities performed freely and without financial reward, and states that such activities are useful for others [1]. The topic of volunteerism is discussed by most researchers; however, the common point in all these descriptions is that a voluntary activity is a work performed free of charge and without wages, and the work's merit is considered the true remuneration for the volunteer. Even many people consider volunteers as inexperienced persons without skill, however, 
the question is: "What kind of work can be considered voluntary activity?" $[1,2]$.

Volunteers with major influence on different levels of the society, provide many economic and social benefits. According to the available statistics in various countries, voluntary activities had an important role in the economy of those countries [2]. Based on the research by the Institute for Volunteering (2005), the monetary value of volunteerism is estimated as USD 280 billion. Statistics Canada reported that in 2000 more than 6.5 million $(27 \%)$ Canadians performed voluntary work, which was worth approximately 1.05 billion hours. In 2007, 12.5 million Canadians or $46 \%$ of the total population of 15 years and above volunteered; collectively, the work value of these volunteers was estimated 2.1 billion hours of volunteer work equal to 1.1 billion full-time works. Also, the research by the Institute for Volunteering (2010) announced that 61.8 million Americans volunteered that in general, this number reached 8 billion hours of volunteer work in 2008. Out of these 61.8 million volunteers, 12.9 million were involved in non-profit organizations and the value of volunteering work in 2010 was estimated USD 160 billion. It was also reported that the volunteering value was close to $10 \%$ of the total American workforce and $5 \%$ of gross national product [3].

Considering the importance of volunteerism, the United Nations named the year 2001 as the International Year of Volunteers. However, it is a difficult task to prove the existence of a sustained, continuous, and widespread commitment by governments, organizations, and communities to promote the use of volunteers. On the contrary, some evidence demonstrates that using the volunteering force is on the decline. Therefore, it seems optimistic to argue that naming the year 2001 as "International Year of Volunteers" would lead to heighten awareness on the importance of utilizing the volunteering workforce that the major part of it is comprised of native people. The desire to help is a principal aspect of human nature. Human beings, more or less possess a kind of behavior that helping others is a component of its nature, and such behavior can be addressed as volunteerism [2].

In the social dimension, volunteering can add to social capitals. Social capital is commonly referred to as one of the most important results of volunteering and volunteer work. In general terms, social capital is summarily described as a background character, patterns of social commitment, belief, and mutual commitment between the individuals. It can be said that volunteering is the heart of social capital. When you help a poor person and he/she thanks you, it certainly gives you a good feeling, or when you perform a good volunteering act, it provides you satisfaction and also adds to your social capital [1-3].

In societies that are impacted by accidents and disasters, volunteering can be performed through different forms, and it depends on the extent and dimensions of the accident. Volunteer citizens are mostly on the frontlines of response to accidents and disasters and reach the scene to provide help ahead of advanced relief forces [2] During major accidents, a major part of efforts to provide aid and resilience taken-up by volunteering organizations such as Red Crescent are comprised of volunteer citizens [4]. In spite of the presence of highly specialized and capable emergency management systems, normally at the time of emergency situations, ordinary citizens are the first to appear at the scene of the accident and remain on the scene for a considerable time after official services are provided. Citizens mostly have a vital role in providing aid and responding and rendering improvement to the ones impacted by the accident, and they can provide valuable assistance to the official relief agents [5-7]. Also, after the earthquakes in Bam and Eastern Azerbaijan province, Iran, a great number of citizens rushed to aid the people impacted by the accident, and volunteer groups were formed in Tehran to mobilize the capabilities of local people; strengthening such groups to provide aid and relief when major accidents occur, is one of the examples for volunteering activities $[8,9]$.

Participation of citizens is one of the basic principles of disaster risk reduction and building up resilience. Nevertheless, in most developing countries, crisis and emergency management relies, to a great extent, on the professional workforce; and in various forms, volunteers are affiliated with official organizations [2]. Persons and groups who operate outside such systems are mostly seen as intruder or even responsible for the accident and their efforts are often undervalued [10-13]. This issue was clearly observed in the earthquake that hit Eastern Azerbaijan province, and some of the people who came from various regions to help the earthquake affected areas were detained by law enforcement officers or were taken as intruders.

There are three different viewpoints with regard to volunteer function in accidents and disasters. The first viewpoint, referred to the aforementioned case, argues that volunteers disrupt the function and response of professional forces in accidents and disasters; the second viewpoint considers volunteers as a valuable resource for organizational response when accidents and disasters occur, and the third viewpoint considers independent efforts by volunteers as important and vital for recovery 
and rehabilitation of the community, and for the professional forces [14].

Quarantel and Stallings pointed out 3 principal activities of emergency volunteer groups: risk assessment, response operations, and coordination, and regard their activities as small-scale and low-risk activities such as: clean-up, providing food materials and equipment, driving and transportation, emotional support for victims, medical and psychological help, construction, search and relief and rescue, translation, registering the volunteers and entering data. Aside from these activities, more complicated activities by volunteers such as setting up wireless infrastructures in accidents and disasters are reported [15]. Based on the danger of disasters throughout the world due to population growth, urban development, and climate change [3], it is likely that "informal volunteers" provide much more additional capacity needed to respond to emergency situations and disasters in the future. The current article aimed at examining the role of informal volunteers in emergency situations, accidents, and disasters.

\section{Materials and Methods}

The current review article aimed at examining the role of volunteer citizens in accidents and disasters. For this purpose, the keywords as informal volunteers in disasters, the challenges volunteer citizens face in accidents and disasters, and informal volunteers and disasters were searched in the domestic and foreign electronic databases including SID, Magiran, Iran Medex, ISC, Google Scholar, Pubmed, ISI, and Scopus from 2000 to 2016.

\section{Results}

Approximately, 17000 articles were found in this field, out of which 50 articles were selected and examined. The current article attended to the issue that ordinary citizens voluntarily offer their time, knowledge, skills, and resources to help others in the time of crisis. A summary of researches regarding the function of citizens in emergency and crisis situations were discussed, and definitions of voluntary activities were examined and considered in emergency, accidents, and disaster situations. The article argued that such definitions were not valid enough to fully recognize and value the volunteering activities and participation of citizens at such situations. In the current article, after identifying "emergency" and "developed" voluntary activities as the 2 principal informal voluntary activities, the definitions of crisis and emergency management were discussed. Particular attention was paid to the increasingly "digital voluntary activities" due to more access to information technology and complex communications, and the changing benefits of voluntary activity. Culture and legal responsibility were recognized as principal obstacles to further participation of informal volunteers.

\section{The role of citizens in accidents and disasters}

The role of citizens in emergency situations and crisis management is extensively documented in the researches on crisis. Researches challenge the common belief that natural disasters lead to chaos and disorder, that citizens become passive, and terrified victims or take part in antisocial behaviors such as looting and plunder; but in fact, individuals and groups in general become more cohesive than the "normal" times, and usually with group work they overcome the challenges arising from the disaster $[16,17]$. Sociological researches provided important insights in collective behavior and organizational reaction to emergency and accident situations. The key share of the work comprises of documents and analysis of emergency behaviors of groups and organization in the time of crisis $[18,19]$.

Early studies on crisis examined the phenomenon of convergence, a process that includes the informal movement of people, messages, and equipment to crisis areas [20]. Contrary to popular viewpoint of chaos and disorder, Fritz and Mattison observed that survivors were more inclined to be impassive, collaborative, and "under social control" of emergency services rather than the ones that were not involved in the accident and appeared on the scene of accident to offer aid.

When encountering disasters and accidents, human beings show reactions that can be divided into 5 stages: 1) Contact or impact: This stage occurs a few minutes after the accident. It is usually transient and short; 2) Heroism: It happens in the initial hours after the accident occurs. Individuals feel they should do something and voluntarily they take part in supplying aid; 3) Joy and forgetting sorrow: This stage occurs from a week to several months after the accident. Concurrent with the arrival of aid groups, individuals become hopeful and they may find peace and joy and a feeling of happiness and pleasure; 4) Encountering the reality 2 to 3 months after occurrence of the accident. At this stage, individuals begin to notice the extent of damages and losses; they lose morale, become depressed, anxious, and sensitive, feel an intense loneliness, and eventually there is reorganization which occurs 6 months to 1 year after the accident. Individuals begin their psychological reconstruction, rebuild their lives, and gradually perceive that they should rely on themselves. The failure to fully reach this stage would lead to psychological symptoms and reactions, 
and depression and anxiety remain unresolved [21]. This psychological process strengthens the convergence phenomenon; therefore, in the stage of heroism, even the victims rush to help.

Recently, Kendra and Wachtendorf identified 7 types of "convergence" from reaction to the tragedy of World Trade Center (2001) that included the referees, the distressed (looking for information about family and friends), helpers, curiosity seekers, exploiters, sponsors (encouragement and expression of gratitude to agents providing aid at emergency situations), and mourners and the organizers of memorial ceremonies. While unaffected people have different motivations to enter the crisis areas, it is expected that convergence would occur in most emergency and crisis situations. Despite the good intentions of most citizens, convergence can create problems and challenges for crisis management. Aufder Heide [22] mentions that hospitals and other organizations responding to emergency situations are often inundated with requests for information and financial help. Unwanted financial help may be inappropriate or unnecessary and would require resources to manage them or dispose of them [23]. This issue can impede emergency services, especially when the transportation and communication infrastructures are experiencing overload. Nevertheless, as Heide emphasizes, convergence is not always bad and "local officials need to understand that whether they like it or not, volunteers will show-up and procedures need to be developed to process these volunteers and integrate them in the response to accidents and disasters".

Early studies on convergence led to the growing interest toward collective behavior and the role of society and other groups in response to emergency and critical situations. Researchers at Disaster Research Center (DRC), based on careful field studies, developed a quadruple typology of organized reaction to disasters $[24,25]$. DRC typology provides a useful framework to understand different types of emergency voluntary activities [26]. In Tehran, Iran, among the projects conducted by the Prevention and Crisis Management Organization of Tehran on participation of citizens in reaction to accidents and disasters, the formation of volunteer groups of neighborhood emergency reaction is carried out in order to mobilize the capabilities of local residents and strengthen them to aid at the time of major accident; it has 3 major parts: first, theoretical and practical training and practices to create the required knowledge, skills, and confidence in volunteers for effective response to crisis; second, organizing volunteer groups to coordinate activities, preserving their readiness in the long-term with roles and functions, and specific methods, and the third part, equipping groups with uniforms, tools, and needed equipment.
In the overall process, the neighborhood's emergency reaction volunteer groups are capable to assist in the following instances: identifying the potential risks present in the neighborhood, assessing the neighborhood's vulnerabilities, formulating an integrated strategy for disaster risk management including prevention, response, and recovery through increasing the resistance of buildings and infrastructure facilities by carrying out practical measures (such as building up resistance), and increasing the capacity of the crisis management official system at national, regional, and local levels, helping people, neighborhoods, and civil organizations to reduce their vulnerability through increasing their readiness and capacity in confronting crisis, recognizing the role and duties of the society in stages of readiness, response, and reconstruction $[8,27]$.

\section{Voluntary activity in accidents and disasters}

Despite the key role that ordinary people play at times of crisis, officials often consider their activities as something outside or separate from the official emergency and crisis management system. Even the trained subjects, volunteer, and ordinary citizens engaged into such activities to help at the time of accident and disasters are considered intruders by the authorities [28, 29]. Experts and volunteers of official organizations are the legitimate players, while others who are not part of the system are often taken as unlawful and impeding to the effective response and should be managed effectively. Ordinary people can acquire legitimacy as a credible volunteer or becoming officially affiliated with the system. This issue can be observed in the efforts by organizations to recruit volunteers, such as volunteers that the Red Crescent Society or the Red Cross calls upon ordinary citizenry in the emergency situations. Organizations can provide help by offering services and equipment, or by utilizing informal volunteers at the time of accidents and disasters; this is when the native volunteers of disaster stricken communities can play an important role to help and respond at the time of accidents and disasters [8].

Forty types of natural disasters are identified in the world; 32 types of it occur in Iran and in this regard Iran is among the 10 disaster-prone countries in the world and ranks 4th in Asia [3]. Many countries that suppose they possess extraordinary capability in the field of aid and rescue, do not have the power to respond during the time of hard and extensive accidents and even lose a number of their aid and rescue forces, and this shows that the most important component alongside advanced rescue equipment is the trained and skilled and experienced human resources and utilization of available human capacities including volun- 
teers and citizens. On the other hand, the most important problem that occurs after unexpected accidents relates to human resources and depletion of such resources.

Also, by considering the reduction of this valuable volunteer force in Iran during harsh and horrible accidents, it can be said that, this worthy force is not properly utilized at the time of crisis, and the lack of planning to employ such resources is quite evident; while by employing these valuable resources, they can play a great share in crisis control when accidents and disasters occur, and this issue necessitates planning for voluntary sector in accidents and disasters [30]. In the next section, the definitions for voluntary activities are reviewed. It can be concluded that there is an interest for accurately defining the voluntary activities that to a great extent exclude individuals who act independent of governmental or official organizations.

\section{The definition of volunteering}

The desire to help is a principal aspect of human nature and individuals specifically possess a type of behavior to help others, which is referred to volunteering [2]. Each year, millions of people take part in various volunteering activities. They provide numerous services such as helping the victims of accidents and disasters, medical services, management, and sport services [3]. The primary definitions of volunteering describe volunteers as individuals who help others without expectation of reward and consider volunteering a type of activity in which intention of volunteer is to help others. There are more comprehensive definitions that consider volunteering as a work freely taken up, without expectation of reward, continuous and with planning that helps the behavior that increases other people's welfare and in general is shaped within an organizational environment [2]. Today, volunteers are among the main members of the section of the society that provides services in the treatment sector and play an important role in the treatment services. Volunteers, with the major effect that they have on various levels of the society, provide many economic and social benefits [1]. In this way, numerous financial benefits are derived by employing volunteers in organizations and it is certain that voluntary works provide great assistance to the health sector and other parts of the society [2, 3]. Nevertheless, a considerable discussion exists in this regard as "which activities should be considered voluntary activities" and "who can be referred to as a volunteer" [1].

The term, volunteering has Latin root and goes back to the fourteenth century AD. At that time "volunteer" was referred to a person who was not compelled or constrained to perform a work and proceeded to do that work based on personal inclination. The definition that Cnaan et al. (1996) [31], provided on volunteering is one of the perfect definitions in this regard and like a continuum encompasses different aspects of volunteering (Table 1). Cnaan et al. [31] examined the definition of volunteering throughout a vast range of sectors. The definitions varied, according to the authors' opinion or situation of the organization, in 4 key dimensions: free choice, remuneration, structure, and beneficiaries. The most precise definitions state that voluntary activity should be completely voluntary and requires no compulsion, no reward or even personal interest should not be presented in the voluntary activities; and it is performed through an official organization, and would not include any relationship or similarity (for example, ethnicity) between volunteers and beneficiaries. The broader definitions include activities that have a degree of coercion (for example, voluntary activity as part of school program), reward lower than value of the work and the provided services, performed outside the official organization, and includes individuals with similar background (for example, ethnicity, religion, gender, or residential groups) and even the volunteers personal benefit from the services they themselves provide (for example, groups that help themselves) [32].

Precise definitions are problematic because the free choice and nature of reward may only be known to the volunteers (for example, a person who has volunteered due to religious or moral obligation or may have acted to improve his career prospects, that is the same motivation for commitment and volunteering work). Furthermore, the extent of volunteer activity would be unclear since many activities in this regard are performed by official organizations, and therefore, a major part of the work performed by individuals in many countries and societies become vague as no official organization or Non-Governmental Organization (NGO) exist in the countries to organize volunteer activities, or they are still being developed $[33,34]$.

Additionally, in some cultures, the Western definitions of voluntary activity may seem alien, or their perception of such behavior is an attempt by a foreign culture to dominate them. For example, Robinson and Williams [35] explained that in the Maori culture, the idea of "public service", which is not voluntary as it is not being an optional activity, should be distinguished from voluntary activity according to choice. The need to belong to a community is a citizen's duty. In the Maori community, voluntary work is a cultural commitment. Similarly, Kerr et al. [36] mentioned that cultural and linguistic differences lead to changes in the meaning, and voluntary activities are not generally known in native societies and 
Table 1. Dimensions of volunteer definitions

\begin{tabular}{cc}
\hline Dimension & Group \\
\hline Free choice & Free will (the ability to choose voluntarily) \\
& Relatively unconstrained \\
& Commitment (pledge) for volunteering \\
Reward & None whatsoever \\
& Without expectation \\
& Expenses covered \\
& Low wages
\end{tabular}

Structure

Official

Informal

$\begin{array}{cc}\text { Useful for others } \\ \text { Beneficiaries } & \text { Useful for friends and relatives } \\ \text { Useful for oneself } & \text { lilealth in } \\ \text { Emmergencies and [Disasters [Oluarterly }\end{array}$

islanders of the Torres Strait of Australia, and they cannot attract both the material support and wider attraction, and it has not become official and within the accepted framework of the society it refers to the same particular community. They argue that the concept of volunteer activity should be developed to include the different meanings given to favorable behavior to recognize and appreciate the experiences of the ones that work outside the primary organizations and dominant paradigms. Volunteering is dissimilar in different countries and depends on the culture of individuals. For example, the culture of European countries is different from that of our country, Iran. As an example, in Iran, along with other Islamic countries, there are many instances of endowments and allocation of assets for public benefits and it can be claimed that the fine tradition of charity and voluntary work help the poor and the vulnerable in Iran. National and Islamic beliefs of the Iranian people can be an inspiration for humanitarian and charitable acts and development and prosperity of the country [1].

Commitment of time is also another important dimension in voluntary activities. Voluntary work is described as an activity in which people "give their time" [37] and often is confined to activities that "develop over time" [38] or are "long-term" [39]. For example, Penner et al., defined voluntary activity as a long-term undertaking: "people contemplate and weigh their options before deciding on voluntary activity. In this sense, voluntary activities can be observed in contrast to the intervention of bystanders, which is usually short-term [39]. This distinction between the intervention of bystanders and voluntary activity is based on the hypothesis that crisis conditions leave limited opportunities for deliberation that are apparently needed for voluntary activities. According to Snyder and Omoto [38], emergency situations and accidents provide little opportunity for anticipation and planning, and usually demand immediate and prompt response. Nevertheless, the researches reviewed in the current article demonstrated that the reaction of the citizens to the emergency and crisis situations are usually intentional and a lot more than the "intervention by bystanders", even though the commitment of time is minimum.

\section{Voluntary activity in emergency and crisis situations}

Voluntary activity tends to be defined widely in the field of emergency and crisis situations. Definitions are often centered on voluntary activities and their results instead of volunteers' characteristics and spontaneous motivation. As an example, in an early article on voluntary activity in crisis conditions, Shaskolski [40] defined voluntary activity as follows: "Any act that gives direction to direct or indirect services to other person or persons regardless of whether such an act encompasses the personal benefits of the player himself or not". Similarly, Wolenski [41] argued that voluntary activity is often defined in terms of altruism and in connection with learning, discovery, and self-actualization, meaning that vol- 
untary activities with the motivations of personal benefit, narcissism, and power are ignored. Wolenski considered voluntary activities as: "Any financially uncompensated arbitrary act that is spontaneous or organized, to protect and / or repair of symbols, interests, people, or other values with high priority of personal or group nature" [41].

According to Shalkoski [40], voluntary activities in crisis conditions take 4 shapes: anticipated individual volunteers fulfill the general expectations of the public on individual basis, such as a physician who would rush to help victims; anticipated organized volunteers who would systematically work with organizations such as volunteer firefighters or Red Cross volunteers who are forces related to accidents and their participation are expected and planned; self-motivated or spontaneous individual volunteers who as individuals help in the initial stages of a crisis; for example, in search and rescue activities, which is the same stage of individual heroism; self-motivated or spontaneous organizational volunteers who would place themselves at the organizational service and soon as an emergency or crisis situation occurs, they get into action, such as Red Crescent volunteers and health volunteers.

These volunteers may: (A) Help the specific crisis organization; (B) Officially set up a temporary organization to deal with special crisis conditions; (C) Utilize their own pre-existing non-crisis organization for crisis affairs; or (D) Carry out the tasks related to accidents within an informal network. Similarly, Wolenski [41] identified 4 types of voluntary activities, after the impact: voluntary activity arising from public interest, including groups such as search and rescue, those who help the clean-up after a disaster, and those who help in the effort to find shelter and housing.

These volunteering activities are considered because of the real concerns of volunteers for human safety and welfare of a humanitarian community; organized voluntary activity is considered as arising from communistic public interest such as systematic and irregular aids offered through emergency services, civil defense and other organizations that act in the public general interest; voluntary activities arising from personal interest include citizens and self-help groups organized to protect their own interests against crisis. These groups are considered as selfish because they are primarily at the service of their members' interests. Personal interest includes organizations such as churches, associations, and associations that primarily provide assistance to their own members. These activities are considered as intermediate, because they help those that have common specifications and interests [8].
Emergency management organizations tend to obtain more official and operational definitions of voluntary activities. For example, the United States Federal Emergency Management Agency (FEMA) [42] defines volunteers in the field of national disaster management system: "Volunteer is any individual accepted for performing services guided by the agency (that possesses required authorities to accept volunteering activities) when the individuals enter into action to perform services without any promises, expectations, or reward."Similarly, Emergency Management Australia [43] defines emergency volunteers as persons who are "involved in emergency activities, according to request (whether directly or indirectly) by express or tacit consent of the executive director (anyone designated), or from an individual who has organizational executive authority". These definitions place the volunteer in the framework of official emergency management systems where volunteers act according to the law, policies, and procedures of relevant organizations. The participation that is requested or invited by an agency or other authorities may not be voluntary if a real or imagined commitment exists. Training and credibility are often key requirements of official voluntary action $[44,8]$.

While most organizations maintain these official, operational definitions, the participation by informal, unaffiliated, spontaneous, and non-administrative volunteers is increasingly recognized. For example, the department of Spontaneous Volunteer Management Resource, Australian Government [45] defines spontaneous volunteers as: "Individuals or group of individuals that are invited to participate during and / or after an accident and are not affiliated with any sectors of the existing official emergency management and reconstruction system and may or may not have the relevant trainings, skills, or trade".

Similarly, FEMA [46] distinguishes between affiliated and unaffiliated volunteers and defines the latter as individuals who carry out "help or self dispatch to help in emergency conditions without fully coordinating their activities". FEMA mentions that although unaffiliated volunteers can be a considerable resource, the absence of pre-determined relations with accident management organizations can face the examination of their training or credibility and conformity of their skills with appropriate service jurisdictions, and problems. Despite this broad view, most organizations are concerned about the management of volunteers and their integration in official response to accidents.

\section{Types of informal volunteering}

There are many ways that citizens can take part informally in accidents and crisis management. In this sec- 
tion, 2 broad types of informal volunteering activity are identified; "emergency voluntary activity" and "developed voluntary activity'. "Voluntary digital activity" is recognized as the new form of volunteerism and is the outcome of increasing accessibility and complexity of information technology and communications that can be exigent, or developed [8].

\section{Emergency or immediate voluntary activity}

Emergency voluntary activities include new forms of voluntary activity that happen in response to unmet needs, whether imagined or real. Researchers and emergency situation managers tend to concentrate on challenges related to spontaneous volunteers that formed at the start of emergency or crisis situation [47-50]. Still, it is important to know that new forms of voluntary activity could be preconceived; for example in preventive and preparatory activities that require considerable deliberation, planning, and organization [51, 52].

Cottrell [53] defined the spontaneous volunteer as an individual that is ready to help others when accidents occur. These are people that when a disaster strikes proceed to help and they are not previously affiliated with officially recognized voluntary organizations, they may or may not have relevant trainings, skills, or experiences. The proximity of spontaneous volunteers to the location of emergency or crisis situations means that they often have an important role in early response to an accident. For example, nursing students that after the earthquake in Bam or East Azerbaijan province, Iran, provided aid as immediate volunteers or in the earthquake of 1976 in Tangshan, China, more than 300000 people were brought out alive from the rubble and rescued by forming the aid and rescue teams $[8,54]$. However, while the spontaneous voluntary activity should be foreseen and planned, it cannot be relied upon. Helsloot and Ruitenberg [12] recorded situations in which the psychological impact related to mass fatalities had made the citizenry impassive, and cultural factors led to inaction and reliance on emergency services.

Initiative and innovation are the key characteristics of emergency volunteers' activity. Severe accidents often create unexpected conditions and problems that need initiative and innovation $[8,55]$. Studies on initiative and innovation in the emergency and crisis situations tend to concentrate on official organizations [56-58]. Nevertheless, Kendra and Wachtendorf [8, 49] by considering the community's innovation and natural disasters mentioned that innovation is a capacity or process that by its virtue, a society performs a new act to encounter crisis, whether it is a potential crisis or the one that has already occurred. Many innovative strategies and utilization of resources occur in the response phase in which immediate need dominates most other issues.

The risk of incompatibility or less favorable consequences tend to, for understanding immediate action, be considered as acceptable risk. The need for pre-disaster and post-crisis innovation is felt increasingly [59, 60]. As a result, the activities of emergency or immediate volunteers very likely happen in response to accidents and immediately after emergency and crisis situations, especially when citizens came to believe that the needs of those impacted by the accident are not met by official organizations. An early study on accidents and disasters showed that most groups remained at the scene of an accident or disaster only for a short time, usually a few hours or a day $[8,61]$. However, some groups may remain active for longer periods and some may lead to formation of organizations for future needs. For example, Atsumi and Goltz [62] explained how some volunteers after experiencing the earthquake at Kobe, Japan, remained active at other natural disasters, and how the active volunteers' network of Nippon disasters (National Voluntary Organizations Active in Disaster, NVOAD) became an organization after Kobe earthquake.

Emergency or immediate volunteers often have a "real-time" viewpoint of issues and problems that confront people, and they can adjust themselves and reactions to local needs. Contrary to the emergency services and other official response organizations, they seldom come forward with pre-determined rules, strategies and technologies that may limit effective local response [63].

It is important to realize that most emergency volunteer activities are less visible and do not lead to official organizations. Smith et al. [64] described the vital role of ordinary people of Haiti who helped in translation of their language and culture to help the implementation of medical services assessment system conducted after the 2010 earthquake. Furthermore, as previously discussed, different cultural perceptions may mean that cooperation activities are not at all considered as voluntary $[8,65]$. The potential benefits of applying local knowledge and other native forms in emergency and crisis management are widely recognized at present $[66,67]$. Fernandez et al. [50] identified 2 main risks in connection with spontaneous volunteers. The first one includes the failure of emergency directors in the effective use of volunteers, (health and treatment volunteers and specialist) that has the potential of loss of life and injury, and damage to property and general weak perception of emergency/crisis response. 
The second is the case of volunteers with untrained operations, uncoordinated (ordinary people) that may disrupt organized response and reduce available resources for people impacted by a disaster. For example, after the 1999 earthquake in Golcuk, Turkey, in which 17000 people lost their lives, emergency services tried to gain access to the disaster area, which was experiencing 32 kilometers of traffic because of spontaneous volunteers [68]. Also, the risk for the actions of untrained and uncoordinated volunteers would hurt the survivors, emergency responders, and the volunteers themselves. Although untrained citizens rescued almost 800 victims in the 1985 Mexico City earthquake, 100 rescuers lost their lives in the attempt to rescue others. This example can be observed with regard to trained volunteers in the traffic accidents and casualties resulting from earthquake that because of unsound transportation leads to spinal cord injury of the victims [69]. Liath [47] mentions that without appropriate training and support, these volunteers, in turn, can be traumatized and by becoming victims of the disaster, may need a lot more services, that should be provided to them.'

\section{The activities of developed volunteers}

Groups and organizations without emergency or critical function at the time of crisis hand over most of their activities to the developed volunteers. These volunteers are usually a part of an existing social group such as chamber of commerce, athletic clubs, religious groups, or service organizations. They perform similar to emergency volunteers in an individual form or by forming a new group. These volunteers often have a close understanding of local needs and can meet those needs by delineating the available networks and resources.

In Australia's rural areas, volunteers from organizations such as the Country Women's Association of Australia and Australian Rotary Clubs often play an effective role in the relief and reconstruction by collecting and distributing foods, clothing, and other locally donated products. Sports and recreation clubs can also play important roles in this regard. These clubs, by demonstrating a high degree of cooperation and coordination, worked alongside each other to send convoys to families who had lost their homes, helped remove debris and damaged trees, renewed setting-up enclosures around properties, supplied alfalfa to farmers, and volunteer groups to firefighters $[8,70]$.

In Iran, the early public organizations were religious and charitable groups and assemblies that were common prior to the advent of Islam, and reached its peak by the arrival of Islam and the culture of sacrifice as pillar of the new religion. Charity organizations with massive religious support based on people's belief and trust, at first were set up in centers such as mosques and religious locations and were completely organized spontaneously and popularly. These can be referred to as examples of developed voluntary activities in Iran. These types of organizations comprise a major part of NGOs in Iran with a special station due to the concern that people and the government have toward eliminating poverty, and improving the livelihood of fellow human beings [3].

Increasingly, the activity by companies in response to crisis is a part of the Corporate Social Responsibility (CSR) $[71,72]$. Although researches, to a great extent, focus on the role of financial aids [73-75], some studies considered the role of company volunteers after a crisis. Twigg [52] mentioned that many companies do not wish to provide mere financial aid after a crisis period, and instead, they are after a more active participation. Also, many perceived the changing expectations of their employees who are after something more than financial reward.

\section{Digital voluntary activity: new mode}

The increasing accessibility of information technology and complex communications, sophisticated yet simple, enables the citizenry to participate in crisis and emergency management in new forms, especially, the wide use of social media and web based mapping software allows citizens to freely produce and publish their own information related to the emergency. There are examples of basic use of sites such as Facebook, Telegram, and WhatsApp to share information for more sophisticated use including searching data and crisis surveying. For example, a Facebook page was created on "pictures and documents found after the storm on 27 April, 2011, when a resident of Lester, Alabama, found pictures in the courtyard of his house after the storm hit that area. He established that page to help people can declare the important items that they lost during the storm. During the year that the said page was active, almost 2000 items were returned to their owners" $[8,76]$.

Mayer explained how students of Taft University in Massachusetts, USA, within a few hours after the 2010 earthquake in Haiti set up an online crisis map to document the level of damage and the victims' immediate needs. Information was initially collected from social media such as Twitter and some of the main stream media. Still, extensive live coverage of the disaster was to the extent that students soon began searching data from several hundred online resources. Hundreds of volun- 
teers from the United States and abroad, voluntarily in groups, proceeded to manually process the data and reviewed 1500 reports by using Ushahidi platform (free software, open surveying source).

After a few days, a brief SMS code was launched and was integrated with Ushahidi, and enabled people of Haiti to send SMS messages and state their special needs. By the majority of SMS messages written in Creole Haitian, social media were employed to recruit volunteers from outside of Haiti who translated 10000 messages during rescue and aid operations. The success of these operations led to creation of a standby force, a network of more than 1000 volunteers in 80 countries, and also led to formation of organizations and crisis mapping designs [77].

Progress in information technology and communications makes it possible for mass dissemination of information, and production of information and knowledge [78]. Voluntary Geographical Information (VGI) includes sharing and mapping aerial data through voluntarily collected information by the public [79]. VGI power is based on the notion that information garnered from a group of observers are very likely more accurate than the information obtained from only one observer. Godchild and Glennon [7] mentioned that despite concerns regarding the quality of information produced by "non-experts" apart from the institutional and legal framework, the VGI quality can be close and even better than credible sources.

The rich text information that observers "on location" can provide, and the speed by which it can be updated, are key advantages. Nevertheless, a few challenges exist related to the use of VGI in emergency management. As it cannot be known in advance how much information can be gathered voluntarily and from where it could come from, VGI should be considered only as a supplementary source of information. Also, the quality of data cannot be guaranteed, because potentially, the citizens, intentionally or unintentionally may offer inaccurate information. Citizens also may lean toward very important or severe accidents, and smaller events remain unreported $[8,80]$.

Increasingly, digital voluntary activities very likely become common throughout the world, in crisis and emergency situations. The important point of the strength of crowd sourcing approach is that the volunteers should not spend a long time for participation, and also, they don't need to be near the crisis stricken or emergency area. The increase in digital voluntary activities also means that citizens can participate in crisis management and emergency situations in other countries.

\section{Concepts of crisis and emergency management}

The current article examined some of the methods by which the citizens take part in emergency situations and informal crisis management, that by voluntary spending of their time, knowledge, skill and resources, they rush to help others. Research showed that the citizen convergence in emergency and crisis locations is unavoidable; therefore, emergency services and other organizations should plan to manage the volunteers' participation. This is essential, therefore, the risk of disruption of organizational response by untrained and uncoordinated volunteers is reduced and available resources are not reduced for the ones impacted by the accident. However, it is necessary to maximize the effectiveness of crisis and emergency management by incorporating knowledge, skills, resources, networks, and enthusiasm of ordinary citizens.

Governments and organizations throughout the world increasingly recognized the opportunities and challenges arising from participation of informal volunteers. Many strategies and resources are developed to manage and have such volunteers involved in the rescue and aid operations. Nevertheless, organizational culture, risks, and responsibility remain as considerable obstacles in the path of participation of most informal volunteers in the emergency and crisis management [8].

\section{Emergency and crisis management cultures}

The ability of the citizens and the extent they are able to participate in emergency situations and crisis management depend, to a great extent, on the official structures and organizational regulations. Most developed countries have developed administrative, command and control methods that have their roots in emergency situations and crisis management $[81,82]$. Command and control methods tend to assume that there is a clear distinction between pre-emergency and emergency periods, and the first one is identified with normalcy and the second with chaos and disorder. With this assumption, the role of emergency and crisis organizations is to set up a command staff before chaos and establish control over disorder [83]. However, Quarantelli [84] mentioned that command and control rarely work well even in military campaigns, and there is doubt in its application and effectiveness in non-military fields.

Drabek and McEntire [19] identified a wide range of assumptions underlying command and control methods as 
follows: bureaucratic responses occur in vacuum; information outside the official channels are without value or wrong; standard operating procedures are always active in disasters; deviation from the administrative guidelines is detrimental; citizens do not take part in crisis operations, they become illogical and passive; and ad hoc affairs are upside down. As mentioned above, crisis research challenged many of these assumptions. Findings showed that citizens tend to have a more cohesive and interactive social behavior in crisis situations. These findings can be a starting point for an alternative way to manage emergency and crisis situations that includes a flexible command structure [84]. Emergency situations are instead in the following form: a collection of problems that should be resolved with a degree of speed and efficiency with available resources in the social unit" [83].

Dynes argued that this problem solving model resulted from a more realistic collection of assumptions and principles resulting from experimental researches. Emergency situations do not reduce the capacity of people and social structures for cooperation, but instead, they mostly present new challenges; the existing social structure is the most effective way to attend these challenges. Therefore, Dynes believed that an "open system" is needed in which "reward of action is placed on flexibility and innovation among various social units, and these efforts are coordinated. Objectives should be directed toward problem solution rather than avoiding chaos. This method can be called network management of crisis. Hierarchical structure is common in organizations. This structure showed its efficiency to maintain the status quo.

In fact there is no structure with a specific meaning in the network structure; as the network structure has virtually eliminated the business tasks within the organization and through long-term contracts with suppliers and distributors, it carries out such tasks. To benefit from the advantages of network management, an interaction is needed between the private and government sectors and this interaction can be used in the management of crisis with unexpected and complicated conditions, and in the preparation phase of the service contract model and issues related to procuring pharmaceutical items, equipment, nutrition, water supply and services; the interaction can be delegated to special companies or volunteers, and in fact to build up the network, and in the response phase by creating a network of hospitals and other collaborating organizations the local and voluntary institutions can be utilized to manage this phase, that unfortunately in Iran, the network structure is not deployed sufficiently, and instead it is based on bureaucratic and hierarchal structure [2-4].
Problem solving models and command and control models are widely aligned with what Harald [55] calls "agility" (creativity, innovation, and adaptability) and discipline (structure, doctrine, and process). A degree of order and discipline is needed for mobilization and management in large organizations. Nevertheless, agility is also needed to ensure extensive coordination and communications. Order and discipline are needed too to ensure speedy and efficient delivery of services under severe conditions, while agility is required to make creativity and compatibility possible in the face of uncertainty. Structure and process are needed to ensure the capability of technical and organizational cooperation of emergency and crisis management organizations; and yet, they should also be sufficiently flexible to have great interaction and participation with spontaneous volunteers and emergency organizations that come to the scene of disaster to help [55]. This argument is supported by Boin and T'hart [85] who argued that "chain of organizations that are actively involved in crisis response networks often become limited and focusing on established and developed organizations is with the limited presence of developing and emergency organizations".

Stallings and Quarantelli [84] proposed 5 key principles to manage emergency situations in the occasion that managers faced emergency groups, and also the management of relationship between crisis managers and informal volunteers. First, they emphasized that unexpected affairs prior to, during, and after a crisis, are unavoidable, because citizens recognize needs that are not met by emergency organizations or other foundations. These needs may be imaginary or real; anyway, the unexpected affairs are likely to occur. Second, they emphasized that although emergency organizations may have concerns about the structure of informal groups, they should admit that their freedom is one of their real strengths [13].

The informal nature of emergency groups means that their efforts are not to carry out new tasks through limited procedures, laws, or regulations. Third, the emergency groups are not always functional, and not always inefficient. Emergency groups may not have an ideal method to attend to a particular problem; yet, the efforts of citizens should be clearly valued, and it should be acknowledged that there are always alternative methods. Fourth, it is important to acknowledge that although these groups may have emerged because of weak perception or needs that have gone unmet by official institutions or organizations, the citizens' groups are not always in opposition to government authority. It is very important for crisis managers to have positive interactions with these groups and not consider them as opposition. Even- 
tually, Stallings and Quarantelli emphasized that emerging phenomena cannot be eliminated through prior planning. Instead, crisis managers should take into account the likely emergency groups and the forms of behavior they would need, for example by encouraging the existing citizen groups, prepare them to carry out emergency or special tasks at times of emergency situations.

Some governmental organizations are completely advanced in integration of official and informal responses to emergency situations. Scanlon et al. [16] documented policies and methods implemented by Smithland Safety Region in the Netherlands that provides optimized utilization of the knowledge, skills and capacities of ordinary people in the management of emergency situations. Some criteria are provided to assist emergency responders to decide how to cooperate with ordinary citizens, existing organizations, and emergency groups.

Policies explicitly allow crisis responders to accept the help of ordinary citizens and organizations provided that the participation is voluntary; the delegated tasks have the least safety risks; the tasks add value to the general emergency response; and citizens perform the tasks that they have the skills and knowledge to successfully accomplish and fulfill. This model, which is more integrated than crisis management, requires that official responders to emergency situations merge with the existing social structures and do not try to reorganize the groups and their activities. It is expected that official responders consider voluntary activity as legitimate by providing them access to the disaster area and furnishing them with special clothing; hence, volunteers could be identified, and notifying them with regard to emergency work. For example, inviting them to participate in meetings related to the progress in response to the crisis.

These innovations are placed in 5 planned stages that begin by the entry of the victims and bystanders to the scene of the accident or disaster and ends by official expression of thanks and gratitude towards the voluntary efforts, and providing counsel and compensation for damages [19]. Execution of these designs may become more complicated under conditions that the responders to emergency conditions would not be able to assess whether the citizens possess the needed knowledge and skills for worthy participation. They may also, out of fear that a volunteer may get hurt, not be inclined to accept help from them [8].

\section{Safety and responsibility}

Sauer et al. [40] mentioned that despite a "global presence" of spontaneous volunteers subsequent to disasters, few studies attended to the issues related to safety and responsibility. Informal volunteers can expose themselves and others to the risk of physical or psychological harm if they participate in rescue and aid activities without required knowledge, skills and equipment and training. A review of 19 organizations identified by NVOAD showed that $15(79 \%)$ organizations during their response activities faced spontaneous volunteers; $18(95 \%)$ organizations reported that they did not check the background of spontaneous volunteers. Only 10 $(53 \%)$ organizations provided on time training, while 8 organizations reported damage to the volunteers. One organization reported that 1 spontaneous volunteer claimed compensation from them, and 3 organizations complained of the acts of spontaneous volunteers. Only 6 organizations $(32 \%)$ believed that they trusted the performance of spontaneous volunteers $[8,40]$.

Orloff [86] identified 2 risks of major responsibility for crisis management organizations due to spontaneous volunteer participation. The first case was that volunteers or their families complained against the organization because of the death, injury, or damage sustained as the result of voluntary activities, and the second case was that the recipients of aid from the organization complained about unintended consequences or consequences that had not been anticipated from the volunteers' operations. In the United States, there are confusions about the responsibilities that result from complicated rules, inconsistent support from one state to another and the often multiple dependencies of volunteers that obscure the lines of responsibility on protection [86].

Eburn [87] discussed the announced laws in some of the Australian states that limited the responsibility of "good Samaritans" or "gratuitous do-gooders" and volunteer members of the social organizations. These laws are intended primarily to protect the people in charge of medical emergencies and when life is threatened; for example providing first aid and medical care. The important point is that laws do not apply to the do-gooders who protect the victims' properties. Those who provide emergency aid should act with good intentions (ie, their intention should be to help the victim) without expecting payment or other reward. Although most laws intend to protect volunteers from personal liability, the organization that they voluntarily work for may still be held accountable for their conduct [87]. However, Saaroni [88] in his study on spontaneous volunteers' management in the state of Victoria, Australia, identified few complaints against the government for the performance of spontaneous volunteers and mentioned that lawsuits against volunteers were uncommon. 
While there is a need for further research on volunteers' legal responsibility and their safety, the risks associated with informal volunteer activity can be reduced to a minimum. Hospitals usually manage the management of associated risks by pre-planning the use of volunteer health professionals trained for such situations [89]. Through registration, training, certifying, proper allocation of tasks, and monitoring of volunteers, safety can be increased and risks associated with liability can be reduced [40]. Nevertheless, these measures are unlikely to be effective when there are informal and emergency volunteer activities. Therefore, managers of emergency situations should adopt themselves with what is happening at the scene of accident and have interaction with a variety of volunteers.

One of the basic issues is the complexity of operational environment in the accidents; and disaster and crisis managers should maximize their working relationship with volunteers and specialist workers. These working relationships are direct or indirect. The existing challenge in the work with volunteers within these relationships assures that the culture of emergency situation organizations is understood clearly [1]. It is important to realize that the capacity of informal volunteers may be limited in some countries or in regions in which the governments and institutions are weak or do not exist. Laws to protect health and safety of volunteers and recipients may be limited. This issue manifested itself in the aftermath of the 2010 earthquake in Haiti when a group of 10 Baptist missionaries from the state of Idaho in the United States were arrested when trying to cross the Haiti-Dominican Republic border with 33 children from 2 to 12 year old [29].

Later it became known that many of these kids were not abandoned or orphan. Questions were raised regarding the intention of that group and it was found that their leader had financial problems and possibly he was after financial reward from homes adopting these children. It was also clarified that one of the legal counselors of that group was under prosecution for alleged sex trafficking in El Salvador [53]. Although it was uncommon, examples of this kind highlight the need to develop the capacities and monitoring methods and management of informal volunteer contributions in crisis and emergency situations. Volunteers should be aware of potential risks that they may sustain due to their participation in emergency situations and should be prepared to accept all responsibilities associated with their commitment. The challenge facing specialist workers who work directly and indirectly with crisis organizations is to find effective and useful methods for support, training, consul- tation, and assistance to volunteers in a complex legal environment [4].

\section{Conclusion}

Ordinary citizens who voluntarily offer their time, knowledge, skills, and resources to help others at the time of crisis demonstrate a great resource for crisis and emergency management. Researches examined in the current article demonstrated that volunteers unintentionally become active at the time of crisis; therefore, it is very important that emergency services and other organizations are prepared to cooperate with them and coordinate their efforts with these groups. It is necessary to ensure an effective response and avoid duplication of aid; it is also required to prevent volunteers to place themselves in conditions that they may get hurt or may injure others.

To increase the efficiency in the disaster response systems, the responsible government officials should reach a level of understanding on the function of volunteers in accidents and disasters, that without a correct understanding, the function of planners in selection and formation and deployment of volunteer forces would not take place as needed, and deployment of volunteer forces would be based on the past experience and would not be realized in a principled and planned manner. To improve the harmony in response and recovery operations in accidents and disasters, coordination should be created between professional and volunteer forces to better understand the roles and challenges facing them.

There are many examples of governments, corporations, and organizations throughout the world that are in the process of cooperating and coordinating their activities with informal volunteers. This is generally done by registering the volunteers and providing them with training programs before an accident or disaster. Still, when voluntary activities become very informal and emergency, these measures are unlikely to succeed. Therefore, it is important that emergency situation managers adapt themselves to what may happen at the scene of accident and be prepared to interact with a diverse range of volunteers. An attempt to merge the informal volunteers with formal systems may have adverse results and contravene the compatibility, innovation, and response of informal volunteers to emergency and crisis management. Considering the changing conditions of crisis and the issue of initiative and innovation of emergency volunteers, hierarchal structure cab be substituted by network structure management. To benefit from the advantages of network management an interaction between private and gov- 
ernment sectors is needed, and this interaction and the network management can be used in crisis management in which conditions are unexpected and complicated. However, in Iran, unfortunately, network structure is not employed much, and efforts are based on bureaucratic and hierarchal structures.

More research is needed to investigate the issue of how organizational culture and structure are changing to emphasize the importance of informal voluntary activities, and how associated legal obligations and safety concerns are managed. These researches are vital if there is an intension to develop more compatible and adaptable models of emergency situation management that benefit from capacities and flexibilities available in the community and between the communities.Based on the studies in this field, it can be concluded that more adaptable and comprehensive models of emergency and crisis management are needed to utilize the capacities and flexibilities available within and between communities, and trying to command and control the actions of citizens is misleading and has adverse results.

\section{Acknowledgements}

This research did not receive any specific grant from funding agencies in the public, commercial, or not-forprofit sectors.

\section{Conflict of Interest}

The authors declared no conflicts of interest.

\section{References}

[1] Aminizadeh M, Mahmoodzadeh A, Saberinia A, Aminizadeh A. [The relationship of motivation factors and satisfaction of Kerman Province health volunteers in unexpected events (Persian)]. Journal of Management and Medical Informatics School. 2014; 2(1):65-57.

[2] Aminizadeh M, Eslamishahr Babaki M, Beyramijam M, Aminizadeh M, Sheikhbardsiri H. Prioritizing motivational and satisfactorily factors of volunteer medical and health personnel in natural disasters. Health in Emergencies and Disasters Quarterly. 2016; 1(2):79-88.

[3] Aminizadeh M. [Volunteer management in sport (Persian)] Kerman: Kerman University of Medical Sciences; 2016.

[4] United Nations Volunteers. 2011 state of the world's volunteerism report: Universal values for global well-being [Internet]. 2011 [Updatetd 2011 December 05]. Available from: https://www.unv.org/publications/2011-stateworld $\%$ E2 $\% 80 \% 99$ s-volunteerism-report-universal-valuesglobal-well-being
[5] Atzet I. Post-crisis actions to avoid international child trafficking. Journal of Law and Family Studies. 2010; 12(2) 499_ 510.

[6] Haworth B, Bruce E. A review of volunteered geographic information for disaster management. Geography Compass. 2015; 9(5):237-50. doi: 10.1111/gec3.12213

[7] Goodchild MF, Glennon JA. Crowdsourcing geographic information for disaster response: A research frontier. International Journal of Digital Earth. 2010; 3(3):231-41. doi: $10.1080 / 17538941003759255$

[8] Whittaker J, McLennan B, Handmer J. A review of informal volunteerism in emergencies and disasters: Definition, opportunities and challenges. International Journal of Disaster Risk Reduction. 2015; 13:358-68. doi: 10.1016/j.ijdrr.2015.07.010

[9] Tehran Disaster Mitigation and Management Organization. [Formation of neighborhood groups, volunteer emergency (Persian)] [Internet]. 2014 [Cited 2014 May 2]. Available from: http://tdmmo.tehran.ir

[10] Fritz CE, Mathewson JH. Convergence behavior in disasters; A problem in social control. Washington D.C.: National Academy of Sciences-National Research Council; 1957.

[11] Stallings RA, Quarantelli EL. Emergent citizen groups and emergency management. Public Administration Review. 1985; 45:93-100. doi: 10.2307/3135003

[12] Helsloot I, Ruitenberg A. Citizen response to disasters: A survey of literature and some practical implications. Journal of Contingencies and Crisis Management. 2004; 12(3):98-111. doi: 10.1111/j.0966-0879.2004.00440.x

[13] Shaskolsky L. Volunteerism in disaster situations. Columbus: Disaster Research Center, Ohio State University; 1967.

[14] Cottrell A. A survey of spontaneous volunteers, Australian red cross research report. Townsville: James Cook University; 2012.

[15] Wachtendorf T, Kendra JM. Considering convergence, coordination, and social capital in disasters. Newark: University of Delaware; 2004

[16] Scanlon J, Helsloot I, Groenendaal J. Putting it all together: Integrating ordinary people into emergency response. International Journal of Mass Emergencies and Disasters. 2014; 32(1):43-63.

[17] Perry RW, Lindell MK. Understanding citizen response to disasters with implications for terrorism. Journal of Contingencies and Crisis Management. 2003; 11(2):49-60. doi: 10.1111/1468-5973.1102001

[18] Whittaker J, McLennan B, Handmer J. A review of informal volunteerism in emergencies and disasters: Definition, opportunities and challenges. International Journal of Disaster Risk Reduction. 2015; 13:358-68. doi: 10.1016/j.ijdrr.2015.07.010

[19] Drabek TE, McEntire DA. Emergent phenomena and the sociology of disaster: Lessons, trends and opportunities from the research literature. Disaster Prevention and Management: An International Journal. 2003; 12(2):97-112. doi: $10.1108 / 09653560310474214$

[20] Barton AH. Communities in disaster: A sociological analysis of collective stress situations. New York: Doubleday; 1969. 
[21] Fayyad J, Sampson NA, Hwang I, Adamowski T, AguilarGaxiola S, Al-Hamzawi A, et al. The descriptive epidemiology of DSM-IV Adult ADHD in the World Health Organization World Mental Health Surveys. ADHD Attention Deficit and Hyperactivity Disorders. 2016; 9(1):47-65. doi: 10.1007/ s12402-016-0208-3

[22] Der Heide EA. Convergence behavior in disasters. Annals of Emergency Medicine. 2003; 41(4):463-6. doi: 10.1067/ mem.2003.126

[23] Holguín-Veras J, Jaller M, Van Wassenhove LN, Pérez N, Wachtendorf T. Material convergence: Important and understudied disaster phenomenon. Natural Hazards Review. 2014; 15(1):1-12. doi: 10.1061/(asce)nh.1527-6996.0000113

[24] Brictson, RC Editor. Symposium on emergency operations. Santa Monica, California: System Development Corporation; 1966.

[25] Dynes RR. Organized behavior in disaster. Lexington: Heath Lexington Books; 1970.

[26] Salvation Army. About the Salvation army [Internet]. 2014 [Updated 2015 February 4]. Available from: http:/ / www.salvationarmyusa.org/usn/about

[27] khankeh $\mathrm{H}$ and colleagues. [Hospital preparedness in disasters and emergencies; The country program (Persian)]. Tehran: University of Social Welfare and Rehabilitation Sciences; 2013.

[28] Aminizadeh M. [Relations among the motivational and satisfaction factors in volunteer forces in sport associate of Kerman Province (Persian)] [MSc. thesis]. Kerman: Shahid Bahonar University of Kerman; 2011.

[29] Meier P. Human computation for disaster response. In Michelucci P, editor. Handbook of Human Computation. New York: Springer; 2013.

[30] Hess JM. Creating new futures: Settling children and youth from refugee backgrounds. Refuge. 2016; 32(1):89-92.

[31] Cnaan RA, Handy F, Wadsworth M. Defining who is a volunteer: Conceptual and empirical considerations. Nonprofit and Voluntary Sector Quarterly. 1996; 25(3):364-83. doi: 10.1177/0899764096253006

[32] Council of Australian Governments. National strategy for disaster resilience: Building our nation's resilience to disasters. Canberra: Council of Australian Governments; 2011.

[33] United Nations Development Programme. State of the world's volunteerism report: Universal values for global well being. New York: United Nations Development Programme; 2011

[34] Wilson J. Volunteerism research. Nonprofit and Voluntary Sector Quarterly. 2012; 41(2):176-212. doi: $10.1177 / 0899764011434558$

[35] Robinson D, Williams T. Social capital and voluntary activity: Giving and sharing in Māori and non-Māori society. Social Policy Journal of New Zealand 2001; 17:52-71.

[36] Kerr L, Savelsburg H, Sparrow S, Tedmanson D. Experiences and perceptions of volunteering in Indigenous and non-English speaking background communities. Adelaide: University of South Australia; 2001.
[37] Wilson J, Musick M. Who cares? Toward an integrated theory of volunteer work. American Sociological Review. 1997; 62(5):694-713. doi: 10.2307/2657355

[38] Snyder M, Omoto AM. Volunteerism: Social issues perspectives and social policy implications. Social Issues and Policy Review. 2008; 2(1):1-36. doi: 10.1111/j.1751-2409.2008.00009.x

[39] Penner LA. Volunteerism and social problems: Making things better or worse? Journal of Social Issues. 2004; 60(3):645-66. doi: 10.1111/j.0022-4537.2004.00377.x

[40] Sauer LM, Catlett C, Tosatto R, Kirsch TD. The utility of and risks associated with the use of spontaneous volunteers in disaster response: A survey. Disaster Medicine and Public Health Preparedness. 2014; 8(1):65-9. doi: 10.1017/ dmp.2014.12

[41] Wolensky RP. Toward a broader conceptualization of volunteerism in disaster. Nonprofit and Voluntary Sector Quarterly. 1979; 8(3-4):33-42. doi: 10.1177/089976407900800306

[42] Federal Emergency Management Agency Glossary [Internet]. 2014 [Updated 2015 May 8]. Available from: https:// www.fema.gov/glossary-terms

[43] Emergency Management Australia. Australian Emergency Management Glossary; Manual 03. Canberra: Emergency Management Australia; 1998.

[44] Britton NR. Permanent disaster volunteers: Where do they fit? Nonprofit and Voluntary Sector Quarterly. 1991; 20(4):395-414. doi: 10.1177/089976409102000404.

[45] Australian Government. Spontaneous volunteer management resource kit: Helping to manage spontaneous volunteers in emergencies. Canberra: Commonwealth of Australia; 2010.

[46] Federal Emergency Management Agency. Volunteer and donations management support annex [Internet]. 2013 [Updated 2013 May 6]. Available from: https://www.fema.gov/ media-library/assets/documents/32282

[47] Liath S. Averting a disaster within a disaster: The management of spontaneous volunteers following the 11 September 2001 attacks on the World Trade Center in NewYork. Volunteer Action Centre. 2004; 6(2):11-29.

[48] Barraket J, Keast R, Newton CJ, Walters K, James E. Spontaneous volunteering during natural disasters. Brisbane: Queensland University of Technology; 2013.

[49] Kendra J, Wachtendorf T. Community in novation and disasters. In: Rodríguez H, Quarantelli EL, Dynes RR, editors Handbook of Disaster Research. New York: Springer; 2007.

[50] Fernandez L, Barbera J, Van Dorp J. Spontaneous volunteer response to disasters: The benefits and consequences of good intentions. Journal of Emergency Management. 2006; 4(5):57-68.

[51] Quarantelli EL. Emergent citizen groups in disaster preparedness and recovery activities. Delaware: University of Delaware; 1984.

[52] Twigg J. Corporate social responsibility and disaster reduction: A global over view. London: University College London; 2001. 
[53] Alice Hearst. Between restavek and relocation: Children and communities in transnational adoption. The Journal of the History of Childhood and Youth. 2010; 3(2):267-92. doi: 10.1353/hcy.0.0101

[54] Noji EK, Earthquakes. In: Noji EK, Editor. The public health consequences of disasters. New York: Oxford University Press, 1997.

[55] Harrald JR. Agility and discipline: Critical success factors for disaster response. The ANNALS of the American Academy of Political and Social Science. 2006; 604(1):256-72. doi: $10.1177 / 0002716205285404$

[56] Reuter C, Ludwig T, Kaufhold MA, Pipek V. XHELP: Design of a cross-platform social-media application to support volunteer moderators in disasters. Paper Presented at: The $33^{\text {rd }}$ Annual ACM Conference on Human Factors in Computing Systems. 18-23 April 2015; Seoul, Korea.

[57] Mendonca DJ, Wallace WA. A cognitive model of improvisation in emergency management. IEEE Transactions on Systems, Man, and Cybernetics - Part A: Systems and Humans. 2007; 37(4):547-61. doi: 10.1109/tsmca.2007.897581.

[58] Webb GR, Chevreau FR. Planning to improvise: The importance of creativity and flexibility in crisis response. International Journal of Emergency Management. 2006; 3(1):66. doi: 10.1504/ijem.2006.010282

[59] Castanos H, Lomnitz C. Earthquake disasters in Latin America: A holistic approach. Dordrecht: Springer; 2012.

[60] Knox JA, Rackley JA, Black AW, Gensini VA, Butler M, Dunn C, et al. Tornado debris characteristics and trajectories during the 27 April 2011 super outbreak as determined using social media data. Bulletin of the American meteorological society. American Meteorological Society. 2013; 94(9):1371-80. doi: 10.1175/bams-d-12-00036.1

[61] Smith RM, Dyer GSM, Antonangeli K, Arredondo N, Bedlion H, Dalal A, et al. Disaster triage after the Haitian earthquake. Injury. 2012; 43(11):1811-5. doi: 10.1016/j.injury.2011.07.015

[62] Atsumi T, Goltz JD. Fifteen years of disaster volunteers in japan: a longitudinal fieldwork assessment of a disaster nonprofit organization. International Journal of Mass Emergencies and Disasters. 2014; 32(1):220-240.

[63] Federal Emergency Management Agency. Community emergency response teams [Internet]. 2015 [Updated 2015 June 15]. Available from: https://www.ready.gov/community-emergency-response-teams-cert

[64] Smith K, Hamerton H, Hunt S, Sargisson R. Local volunteers respond to the Renaoil spill in Maketū, New Zealand. Kōtuitui: New Zealand Journal of Social Sciences Online. 2015; 11(1):1-10. doi: 10.1080/1177083x.2015.1009474

[65] Quarantelli EL. Organizational response to the Mexico City earthquake of 1985: Characteristics and implications. Natural Hazards. 1993; 8(1):19-38. doi: 10.1007/bf00596233

[66] Haynes K, Bird D, Carson B. Indigenous experiences and responses to Cyclone Tracy. In: Palutik J, Boulter S, Barnett J, Rissik D, editors. Applied Studies in Climate Adaptation. Oxford: Wiley Blackwell; 2015.

[67] Mercer J, Kelman I, Taranis L, Suchet-Pearson S. Framework for integrating indigenous and scientific knowledge for disaster risk reduction. Disasters. 2009; 34(1):214-39. doi: 10.1111/j.1467-7717.2009.01126.x

[68] Dynes RR, Quarantelli EL, Wenger D. Individual and organizational response to the 1985 earthquake in Mexico City, Mexico. Delaware: Disaster Research Center; 1990.

[69] Hur J. Disaster management from the perspective of governance: Case study of the Hebei Spirit oil spill. Disaster Prevention and Management. 2012; 21(3):288-98. doi: $10.1108 / 09653561211234471$

[70] Wangaratta Four Wheel Drive Club. Track torque [Internet]. 2009 [Updated 2009 March 5]. Available from: https:// www.wangaratta4x4club.org.au/

[71] Chong M. Employee participation in CSR and corporate identity: Insights from a disaster-response program in the Asia-Pacific. Corporate Reputation Review. 2009; 12(2):10619. doi: $10.1057 /$ crr.2009.8

[72] United Nations Development Programme. UN and Deutsche Post DHL sign new 3-year agreement for disaster resilience [Internet]. 2014 [Updated 2014 June 11]. Available from: http://www.undp.org/content/undp/en/home/ presscenter/articles/2014/06/11/un-and-dhl-use-airportterminals-to-make-disasters-less-terminal.html

[73] Zhang R, Rezaee Z, Zhu J. Corporate philanthropic disaster response and ownership type: Evidence from Chinese firms' response to the Sichuan earthquake. Journal of Business Ethics. 2009; 91(1):51-63. doi: 10.1007/s10551-009-0067-3

[74] Muller A, Whiteman G. Exploring the geography of corporate philanthropic disaster response: A study of fortune global 500 firms. Journal of Business Ethics. 2008; 84(4):589-603. doi: 10.1007/s10551-008-9710-7

[75] Muller A, Kräussl R. Doing good deeds in times of need: A strategic perspective on corporate disaster donations. Strategic Management Journal. 2011; 32(9):911-29. doi: 10.1002/ smj.917

[76] Belz K. 'I just can't throw them away': Patty Bullion made Facebook page to help return heirlooms to families [Internet]. 2013 [Updated 2013 April 27]. Available from: http://www. timesfreepress.com/news/local/story/2013/apr/27/i-justcant-throw-them-away/106524/

[77] McAdoo BG, Moore A, Baumwoll J. Indigenous knowledge and the near field population response during the 2007 Solomon Islands tsunami. Natural Hazards. 2008; 48(1):73-82. doi: 10.1007/s11069-008-9249-z

[78] Linders D. From e-government to we-government: Defining a typology for citizen coproduction in the age of social media. Government Information Quarterly. 2012; 29(4):44654. doi: 10.1016/j.giq.2012.06.003

[79] Fishwick C. Tomnod - the online search party looking for Malaysian Airlines flight MH370 [Internet]. 2014 [Updated 2014 March 14]. Available from: https://www.theguardian. com/world/2014/mar/14/tomnod-online-search-malaysian-airlines-flight-mh370

[80] Poser K, Dransch D. Volunteered geographic information for disaster management with application to rapid flood damage estimation. Geomatica. 2010; 64(1):89-98. 
[81] Neal DM, Phillips BD. Effective emergency management: Reconsidering the bureaucratic approach. Disasters. 1995; 19(4):327-37. doi: 10.1111/j.1467-7717.1995.tb00353.x

[82] Quarantelli EL. Disaster studies: An analysis of the social historical factors affecting the development of research in the area. International Journal of Mass Emergencies and Disasters. 2010; 5(3):285-310.

[83] Dynes RR. Community emergency planning: False assumptions and in appropriate an alogies. International Journal of Mass Emergencies and Disasters. 1994; 12(2):141-158.

[84] Quarantelli EL. Disaster crisis management: A summary of research findings. Journal of Management Studies. 1988; 25(4):373-85. doi: 10.1111/j.1467-6486.1988.tb00043.x

[85] Boin A, Hart P. Organising for effective emergency management: Lessons from research 1. Australian Journal of Public Administration. 2010; 69(4):357-71. doi: 10.1111/j.14678500.2010.00694.x

[86] Orloff L. Managing spontaneous community volunteers in disasters: a field manual. Boca Raton: CRC Press; 2011.

[87] Eburn M. Protecting volunteers? Australian Journal of Emergency Management. 2003; 18(4):7-11.

[88] Saaroni L. Managing spontaneous volunteers in emergencies: A qualitative risk-benefit assessment model for local governments in Victoria, Australia [MSc. thesis]. Leicester: University of Leicester; 2014.

[89] Hodge JG. Legal triage during public health emergencies and disasters. Administrative Law Review. 2006; 58(3):627-644. 
